\title{
Análise biométrica de florestas irrigadas de eucalipto nos cinco anos iniciais de desenvolvimento
}

\author{
$\overline{\text { André L. T. Fernandes }}{ }^{1}$, Thaíla de $M$. Florêncio ${ }^{2} \& M$ arianne $F$. de Faria ${ }^{3}$
}

\section{RESU M O}

Neste trabalho o objetivo foi avaliar os efeitos da irrigação e da nutrição mineral no crescimento e produção do eucalipto (Eucalyptus grandis) cultivado na região do Triângulo Mineiro. 0 experimento foi conduzido na Fazenda Escola da U niversidade de U beraba, situada a $850 \mathrm{~m}$ de altitude, em Latossolo Vermel ho Amarelo. Compararam-se tratamentos irrigados e não irrigados, com diferentes níveis de adubação $(25,50$ e $100 \%$ das doses recomendadas, tanto em fertirrigação quanto em adubação convencional). Foram avaliados parâmetros de diâmetro à altura do peito e crescimento ao longo de cinco anos de condução do experimento e determinada a produtividade total de madeira, ao final deste período. Embora ao longo dos anos os resultados tenham sido estatisticamente diferentes observou-se, ao fim do período analisado, que tratamentos irrigados apresentaram maiores valores biométricos, além de maiores taxas de incremento médio anual (IM A). Proximidade de valores pode ter ocorrido em razão das chuvas excessivas no local, tornando a água mais disponível para os tratamentos não-irrigados.

Palavras-chave: madeira comercial, irrigação, adubação

\section{Biometric analysis of irrigated eucalyptus forests in the five initial years of development}

\begin{abstract}
AB STRACT
This research aimed to evaluate the effects of irrigation and mineral nutrition on the grow th and production of eucalyptus (Eucalyptus grandis) cultivated in the Triângulo Mineiro region, M inas Gerais, Brazil. The experiment was conducted at the Farm School of U niversity of U beraba, which has $850 \mathrm{~m}$ of altitude, in Red-Y ellow Latosoil. Irrigated and non-irrigated treatments with different nutritional conditions $(25,50$ and $100 \%$ of the recommended doses) were compared. The parameters of diameter at breast height and growth were evaluated during the period of five years of experimentation, the final productivity of wood was also determined at the end of that period. Even though results were statistically different throughout the years, at the end of the analyzed period it was observed that irrigated treatments showed higher biometric values as well as largest rates of mean annual increment. Proximity of values may have occurred due to excessive rainfall at the site, increasing availability of water for the non-irrigated treatments.
\end{abstract}

Key words: commercial wood, irrigation, fertilization

\footnotetext{
${ }^{1}$ U niversidade de U beraba, Programa de Educação a D istância, Sala 2M 03, Campus Aeroporto, Avenida N enê Sabino 1801, Bairro U niversitário, CEP 38055-500, U beraba, MG. E-mail: andre.fernandes@uniube.br

${ }^{2}$ M estranda em Inovação Tecnológica da U niversidade Federal do Triângulo M ineiro (PM PIT/ICTE/U FTM ) e Engenharia Ambiental pela U niversidade de U beraba. E-mail: thailamello@gmail.com

${ }^{3}$ Engenharia Ambiental, U niversidade de U beraba. E-mail: marianneffaria@hotmail.com
} 


\section{INTRODUÇÃO}

De acordo com a FAO (2010), o Brasil é o segundo país com maior quantidade de florestas no mundo, apresentando quase 477,77 milhões de hectares e o quarto com maior área dedicada à silvicultura, ocupando 5,98 milhões de hectares. Entretanto, o país ainda necessita de informações mais concretas para desenvolver técnicas de manejo mais eficientes e viáveis.

A Sociedade Brasileira de Silvicultura (SBS) apresenta, em relatório estatístico, que em 2008 havia 3,75 milhões de hectares plantados com árvores do gênero do eucalipto. As exportações de produtos de base florestal alcançaram o valor de US\$ 9,1 bilhões no mesmo ano. O setor florestal colabora com 3,4\% da formação do PIB nacional, 5,6\% das exportações, 18,5\% do superávit da balança comercial e 9,0\% dos empregos (SBS, 2010).

Do eucalipto, praticamente todas as partes são aproveitadas (Shimizu, 2006). Das folhas se extraem óleos essenciais empregados em produtos de limpeza e alimentícios, em perfumes e em medicamentos. $\mathrm{O}$ tronco fornece madeira para sarrafos, ripas, vigas, postes, varas, esteios para minas, mastros para barco, tábuas para embalagens e móveis. A fibra é utilizada como matéria-prima para a fabricação celulose e papel. Há uma forte tendência em utilizá-la também para usos mais nobres, como fabricação de casas, móveis e estruturas, em especial nas Regiões Sudeste e Sul, carentes de florestas naturais. Desta forma, a indústria madeireira necessita de florestas altamente produtivas e que possam fornecer matéria-prima de qualidade, com propriedades uniformes, densidade, cor e características tecnológicas que satisfaçam as exigências de mercados, segundo cada produto obtido de seu desdobramento final.

Os reflorestamentos com eucalipto apresentam viabilidade técnica e econômica, mostrando-se muito promissores. A espécie pode ampliar significativamente sua participação na composição da renda agropecuária, com vantagens adicionais, sob a ótica social e ambiental (Cordeiro et al., 2010).

Para que uma floresta de eucalipto tenha produções significativas, uma das técnicas que o produtor pode utilizar é a irrigação que tem, por objetivo, o fornecimento controlado de água para as espécies florestais em quantidade suficiente e no momento certo, complementando a precipitação natural.

Objetivando avaliar a resposta do estresse hídrico de diferentes clones de eucalipto, Vellini et al. (2008) concluíram serem melhores os desempenhos de desenvolvimento dos clones irrigados todos os dias do que daqueles irrigados em intervalos de 6 dias. Diversos trabalhos têm sido desenvolvidos visando maximizar a produtividade de espécies florestais com o uso da irrigação. Sabe-se que esta técnica é amplamente utilizada em frutíferas e hortaliças e sua influência em florestas tem sido, ultimamente, levada em consideração em grandes empreendimentos, dado sempre a relação custo-benefício, pois tal tecnologia exige grandes investimentos (Alencar et al., 2009; Silva et al., 2003). Apesar da controvérsia gerada pela irrigação em silvicultura é notório o fato de que as florestas nativas de Mata Atlântica conseguem ter taxas muito próximas às de plantações de eucalipto quanto ao uso de água no solo e evapotranspiração anual, de acordo com estudos conduzidos em Aracruz, no Espírito Santo (Almeida \& Soares, 2003).
A importância da água na silvicultura do eucalipto foi evidenciada em estudo de Lopes et al. (2005), no qual se relatou a influência da manutenção do regime hídrico no desenvolvimento de mudas de eucalipto mantidas sob diferentes condições de irrigação. Souza et al. (2006) observaram aumento no incremento mensal de $0,445 \mathrm{~m}^{3} \mathrm{ha}^{-1}$ mês ${ }^{-1}$, para cada $100 \mathrm{~mm}$ a mais em precipitação total, de ano para o outro, em experimento realizado na bacia do Rio Doce, em Minas Gerais. Em pesquisa recente observou-se que o fornecimento de água determina positivamente o crescimento do eucalipto, em detrimento das variadas condições de nutrição, já que os maiores valores para a característica analisada foram obtidos nas sequências menos férteis de solo (Balieiro et al., 2008).

Gruber et al. (2006) afirmam que, sendo a irrigação uma tecnologia geradora de incrementos agrícolas, ela poderia oferecer maior adaptação das mudas ao campo, diminuir doenças e até mesmo a lixiviação do solo, além da redução na idade de corte e proporcionar um desenvolvimento mais homogêneo da silvicultura. Todos esses fatores podem causar maior lucratividade para o produtor.

Dentro deste contexto objetivou-se, com esse trabalho, avaliar diferentes estratégias de irrigação e nutrição mineral no desenvolvimento vegetativo e produtivo do eucalipto cultivado nas condições do Triângulo Mineiro, Minas Gerais.

\section{MATERIAL E MÉTODOS}

O experimento foi conduzido no Campus Experimental da Universidade de Uberaba - Fazenda Escola, na cidade de Uberaba, MG, localizada na latitude de $19^{\circ} 44^{\prime} 13$ ' S, longitude $47^{\circ} 57^{\prime} 27^{\prime}$ ' W e altitude de $850 \mathrm{~m}$.

De acordo com Ranzani (1969), o clima de Uberaba é classificado pelo método de Köppen como Aw, tropical quente úmido, com inverno frio e seco. A precipitação anual é de 1474 mm e a temperatura média anual é de $22,6^{\circ} \mathrm{C}$.

A espécie florestal avaliada foi o eucalipto (Eucalyptus grandis) cultivado com e sem irrigação. Em nível de subparcela foram avaliados diferentes níveis de nutrição mineral, em fertirrigação (25, 50 e $100 \%$ da dose total recomendada). Para referência, utilizou-se a codificação representada na Tabela 1.

Tabela 1. Codificação utilizada em referência aos tratamentos e disponibilidade de água nos mesmos

\begin{tabular}{llc}
\hline \multicolumn{1}{c}{ Disponibilidade de água } & Tratamento & Codificação \\
& $100 \%$ adubado & E-IR-A \\
Irrigado & $50 \%$ adubado & E-IR-B \\
& $25 \%$ adubado & E-IR-C \\
Não-irrigado & $100 \%$ adubado & E-NIR-A \\
& $50 \%$ adubado & E-NIR-B \\
& $25 \%$ adubado & E-NIR-C \\
\hline
\end{tabular}

Os tratamentos sem irrigação receberam adubação na forma convencional de aplicação, mantendo-se as mesmas doses de macro e micronutrientes dos tratamentos irrigados. Cada parcela apresentava dimensões de 60 x 53,5 m. A média da área amostral foi de $124,60 \mathrm{~m}^{2}$. 
Antes do início do experimento foi feita a avaliação do sistema de irrigação a fim de se determinar a uniformidade de aplicação de água, obtendo-se o coeficiente de uniformidade de emissão e o coeficiente de uniformidade estatística. A referida análise foi repetida durante todos os anos do experimento, para verificação das condições de funcionamento do sistema de gotejamento em cada tratamento. A vazão média dos gotejadores utilizados no experimento após as avaliações de campo foi de $2,2 \mathrm{~L} \mathrm{~h}^{-1}$ e os coeficientes médios encontrados foram de 95,0 e $94,7 \%$, respectivamente, para a uniformidade estatística e a uniformidade de emissão, permitindo concluir que a operação do sistema era satisfatória, sobretudo para a fertirrigação.

Retiraram-se amostras para análise da água que seria usada no experimento, a qual era advinha do reservatório da fazenda (açude). As análises envolveram estudos das características físicas, organolépticas, biológicas, químicas, bacteriológicas e de metais pesados (Tabela 2). A água foi classificada na classe 3 e pode ter, como usos recomendados para abastecimento doméstico, após tratamento convencional; irrigação de culturas arbóreas, cerealíferas e forrageiras e dessedentação de animais (Brasil, 1986). Também apresentou, pelas comparações de valores de sólidos suspensos, sólidos totais e quantidade de ferro, baixo risco de obstrução de gotejadores (Pizarro, 1990).

Tabela 2. Análise da água utilizada no experimento

\begin{tabular}{|c|c|c|}
\hline Características & Unidades & Resultados \\
\hline $\begin{array}{l}\text { Temperatura } \\
\text { Cor } \\
\text { Turbidez } \\
\text { Sólidos totais } \\
\text { Sólidos voláteis } \\
\text { Sólidos fixos } \\
\text { Sólidos sedimentáveis } \\
\text { Sólidos suspensos } \\
\text { DBO } \\
\text { DOO }\end{array}$ & $\begin{array}{c}\text { Físicas e organolépticas } \\
\text { o- } \\
\mathrm{mg} \mathrm{pt} \mathrm{L}^{-1} \\
\mathrm{FTU} \\
\mathrm{mg} \mathrm{L} \\
\mathrm{mg} \mathrm{L} \\
\mathrm{mg} \mathrm{L} \\
\mathrm{mg} \mathrm{L}^{-1} \\
\mathrm{mg} \mathrm{L}^{-1} \\
\mathrm{mg} \mathrm{L}^{-1} \\
\mathrm{mg} \mathrm{L}^{-1}\end{array}$ & $\begin{array}{c}25 \\
25 \\
4.3 \\
65 \\
44 \\
21 \\
<1 \\
31 \\
2 \\
9\end{array}$ \\
\hline $\begin{array}{l}\text { pH } \\
\text { Condutividade elétrica } \\
\text { Oxigênio dissolvido } \\
\text { Fósforo total } \\
\text { Nitrogênio amídico } \\
\text { Nitrogênio amoniacal } \\
\text { Ferro total } \\
\text { Alcalinidade total } \\
\text { Dureza total } \\
\text { Dureza cálcica } \\
\text { Dureza magnesiana }\end{array}$ & $\begin{array}{c}\text { Químicas } \\
\mathrm{pH} \\
\mathrm{dS} \mathrm{^{-1 }} \\
\mathrm{mg} \mathrm{L}^{-1} \\
\mathrm{mg} \mathrm{L}^{-1} \\
\mathrm{mg} \mathrm{L}^{-1} \\
\mathrm{mg} \mathrm{L}^{-1} \\
\mathrm{mg} \mathrm{L}^{-1} \\
\mathrm{mg} \mathrm{L}^{-1} \\
\mathrm{mg} \mathrm{L}^{-1} \\
\mathrm{mg} \mathrm{L}^{-1} \\
\mathrm{mg} \mathrm{L}^{-1}\end{array}$ & $\begin{array}{c}8 \\
0,8 \\
7,2 \\
0,6 \\
1,2 \\
0,7 \\
0,1 \\
73 \\
38 \\
31 \\
7\end{array}$ \\
\hline Microrganis mos totais & $\begin{array}{c}\text { Bacteriológicas } \\
\text { NMP (colônias } \mathrm{mL}^{-1} \text { ) }\end{array}$ & 250 \\
\hline $\begin{array}{l}\text { Chumbo } \\
\text { Mercúrio } \\
\text { Arsênio } \\
\text { Cobre } \\
\text { Cádmio } \\
\text { Zinco }\end{array}$ & $\begin{array}{l}\text { Metais pesados } \\
\qquad \mathrm{mg} \mathrm{L}^{-1} \\
\mathrm{mg} \mathrm{L}^{-1} \\
\mathrm{mg} \mathrm{L}^{-1} \\
\mathrm{mg} \mathrm{L}^{-1} \\
\mathrm{mg} \mathrm{L}^{-1} \\
\mathrm{mg} \mathrm{L}^{-1}\end{array}$ & $\begin{array}{c}0,001 \\
0,001 \\
<0,001 \\
0,451 \\
0,001 \\
0,001\end{array}$ \\
\hline
\end{tabular}

DBO - Demanda bioquímica de oxigênio; DQO - Demanda química de oxigênio; NMP - Número mais provável
Antes do início do experimento amostras de solo foram coletadas em cada parcela e, posteriormente, submetidas a análises, que foram repetidas anualmente. Também foi realizada a coleta de análise para determinação das características físicohídricas do solo do experimento, apresentadas na Tabela 3.

Tabela 3. Características físico-hídricas do solo do experimento

\begin{tabular}{lc}
\hline Características & Valor \\
Areia & $72,60 \%$ \\
Silte & $5,40 \%$ \\
Argila & $21,96 \%$ \\
Ponto de murchamento permanente & $0,132 \mathrm{~cm}^{3} \mathrm{~cm}^{-3}$ \\
Capacidade de campo & $0,213 \mathrm{~cm}^{3} \mathrm{~cm}^{-3}$ \\
Água disponível & $0,081 \mathrm{~cm}^{3} \mathrm{~cm}^{-3}$ \\
Densidade aparente do solo & $1,47 \mathrm{~kg} \mathrm{dm}^{-3}$ \\
\hline
\end{tabular}

O plantio foi realizado em outubro de 2003 com espaçamento de 4,0 x 1,5 m com aplicação de $2 \mathrm{t} \mathrm{ha}^{-1}$ de calcário dolomítico e com a utilização da formulação de plantio N-P-K 08-28-16 e, para cobertura, a formulação N-P-K 20-00-20, no total de 0,25 e $0,20 \mathrm{t} \mathrm{ha}^{-1}$, respectivamente.

Os dados foram colhidos em ziguezague a partir da primeira árvore mensurável, compreendendo medições de 2004 a 2008, com coleta anual.

Para os trabalhos de campo utilizou-se fita métrica graduada em mm para a mensuração da circunferência das árvores a 1,30 $\mathrm{m}$ do solo (diâmetro à altura do peito - DAP), com posterior conversão para o diâmetro. Utilizou-se um hipsômetro eletrônico para mensuração das alturas, para a locação das amostras e trena para a mensuração da área das parcelas. Para análise estatística de dados utilizou-se o software Statistica 6,0. O cálculo volumétrico exigiu a cubagem de 14 árvores: sete no setor irrigado e sete no setor não-irrigado. A escolha das árvores teve como base o diâmetro à altura do peito médio (DAP médio). A cubagem foi realizada ao serem coletados dois diâmetros ortogonais nas alturas de seções a 0,$10 ; 0,70 ; 1,30$; 2,0 e, a partir daí, de metro em metro. Coletou-se também a altura total e comercial da árvore; enfim se aplicou, para o cálculo do volume sólido da árvore, a fórmula de Smalian (Eq. 1)

$$
\mathrm{V}=\frac{\pi}{4}\left[\left(\frac{\mathrm{A}+\mathrm{a}}{2}\right) \mathrm{L}\right]
$$

em que:

$\mathrm{V}$ - volume da seção do tronco, $\mathrm{m}^{3}$

A - área transversal da seção de maior diâmetro, $\mathrm{m}^{2}$

a - área transversal de menor diâmetro, $\mathrm{m}^{2}$

L - comprimento da seção, $m$

A área transversal de cada seção foi calculada pela Eq. 2:

$$
\mathrm{A}=\frac{\pi \mathrm{d}^{2}}{4}
$$

em que:

d - diâmetro da seção, em m 


$$
\mathrm{V}=\left(\frac{\mathrm{g}_{1}+\mathrm{g}_{2}}{2}\right) \mathrm{c}
$$

em que:

$$
\begin{array}{ll}
\mathrm{g}_{1} & \text { - diâmetro da base, } \mathrm{m} \\
\mathrm{g}_{2} & \text { - diâmetro do topo, } \mathrm{m} \\
\mathrm{c} & \text { - altura da árvore, } \mathrm{m}
\end{array}
$$

Para se obter o volume sólido de cada árvore após a cubagem rigorosa realizada em campo, aplicou-se um fator de forma médio.

\section{RESULTADOS E DISCUSSÃO}

Os dados biométricos médios obtidos estão disponibilizados graficamente na Figura 1, para dados de altura e, na Figura 2, para dados referentes ao diâmetro e à altura do peito (DAP).

Com relação à altura é destacado na Figura 1, em cada marcador, o referente às médias anuais, com linhas de tendência com coeficientes de correlação acima de $97 \%$. Para o ano de 2008 houve proximidade nos valores de altura das parcelas irrigadas e com $100 \%$ da adubação necessária - E-IR-A $(24,16$ $\mathrm{m})$, parcelas irrigadas e com $50 \%$ da adubação necessária - EIR-C (23,69 m) e parcelas não irrigadas e com $100 \%$ da adubação

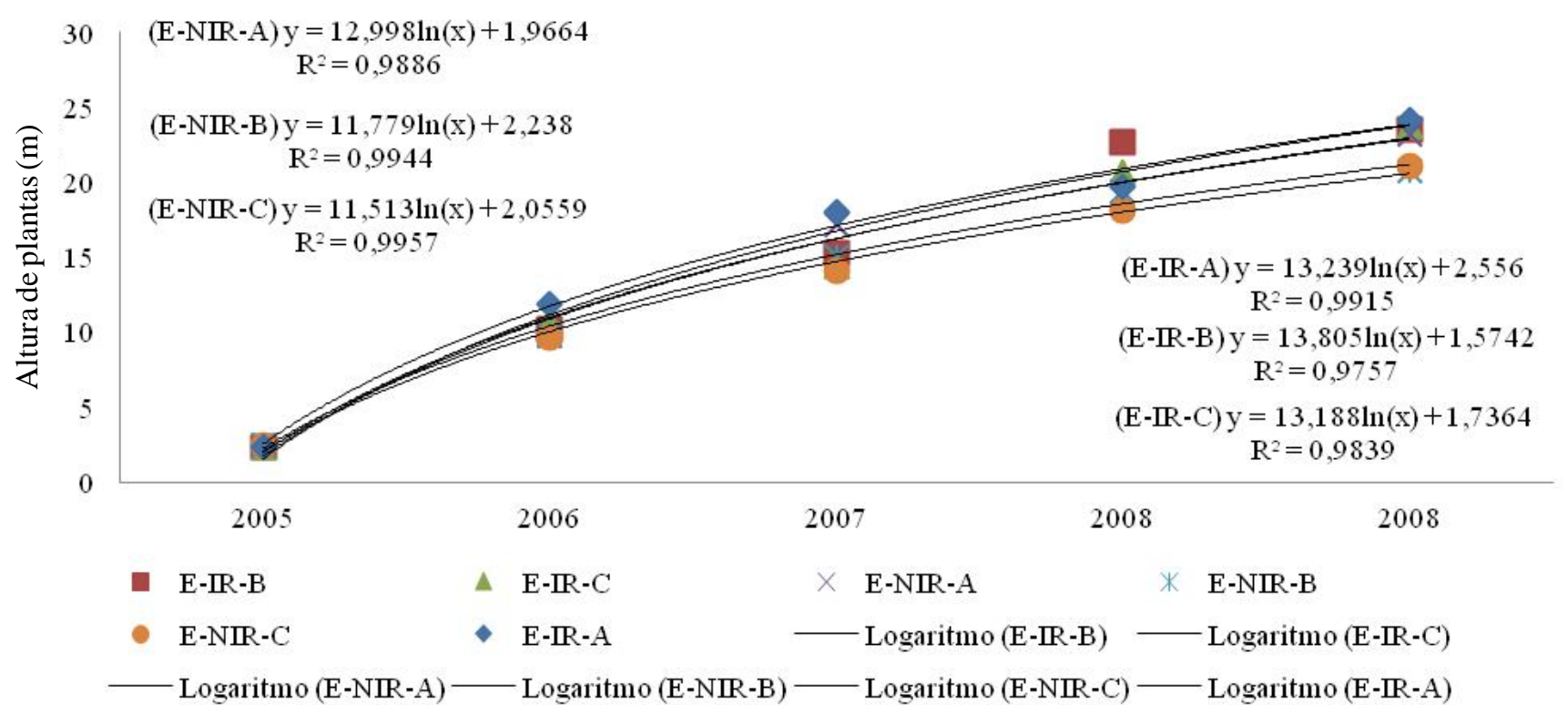

E-IR-A - parcelas irrigadas e com $100 \%$ da adubação necessária; E-IR-B - parcelas irrigadas e com $50 \%$ da adubação necessária; E-IR-C - parcelas irrigadas e com $25 \%$ da adubação necessária; E-NIR-A - parcelas não irrigadas e com $100 \%$ da adubação necessária; E-NIR-B - parcelas não irrigadas e com $50 \%$ da adubação necessária; E-NIR-C - parcelas não irrigadas e com $25 \%$ da adubação necessária

Figura 1. Altura do eucalipto nos cinco anos iniciais com linhas de tendência

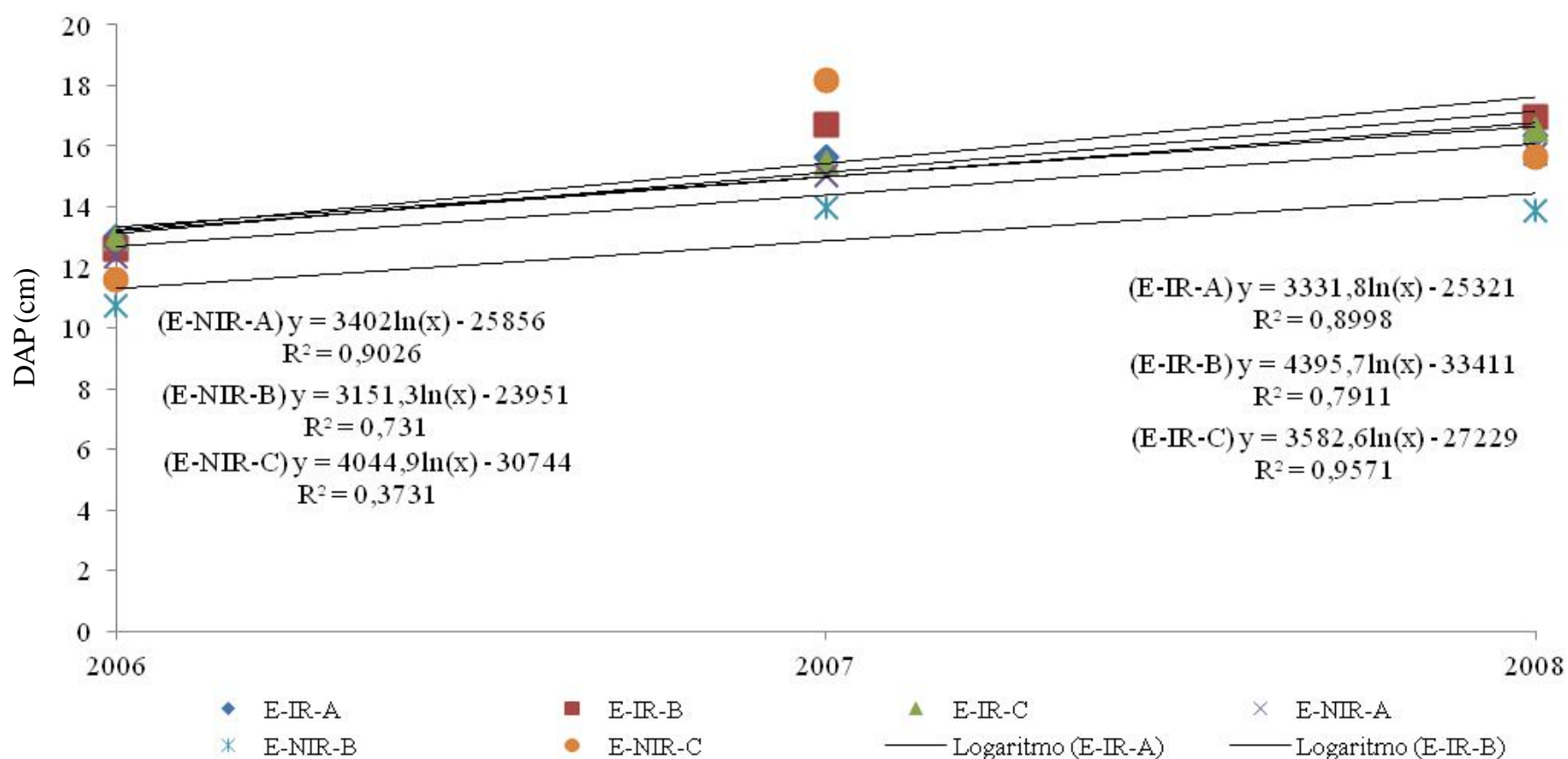

E-IR-A - parcelas irrigadas e com $100 \%$ da adubação necessária; E-IR-B - parcelas irrigadas e com $50 \%$ da adubação necessária; E-IR-C - parcelas irrigadas e com $25 \%$ da adubação necessária; E-NIR-A - parcelas não irrigadas e com $100 \%$ da adubação necessária; E-NIR-B - parcelas não irrigadas e com $50 \%$ da adubação necessária; E-NIR-C - parcelas não irrigadas e com $25 \%$ da adubação necessária

Figura 2. Diâmetro à altura do peito (DAP) do eucalipto nos cinco anos iniciais com linhas de tendência 
necessária - E-NIR-A (23,25 m). A menor altura foi a apresentada pelo tratamento das parcelas não irrigadas e com $50 \%$ da adubação necessária - E-NIR-B (20,75 m).

Embora a predominância para maiores valores de altura tenha sido obtida com o tratamento E-IR-A, observou-se que em 2007 o tratamento E-IR-B superou o tamanho do primeiro em $2,93 \mathrm{~m}$, vindo a ser superado no ano seguinte, com diferença de 0,61 m. Semelhante resultado em diferentes condições, foi obtido em trabalho de pesquisa de Silva et al. (2004), no qual o eucalipto era submetido a irrigação e interferência de concorrência de gramíneas (no caso do experimento, Brachiaria brizantha), e como resultado, espécies que eram tratadas com as condições próximas de campo em relação ao teor de água e com a ausência de $B$. brizantha, apresentaram maior diâmetro total e altura de caule; assim sendo, confirma-se a preferência para um crescimento mais rápido e rentável da madeira, pelo fornecimento de água. Esses autores afirmam que a espécie de E. grandis consumiu mais água do que as outras espécies de eucalipto utilizadas no experimento.

Para as avaliações de diâmetro - DAP, com medições de 2006 a 2008 (Figura 2), as linhas de tendência apresentaram coeficiente de correlação acima de $85 \%$. O maior DAP foi obtido com o tratamento E-IR-B, com 16,97 cm; ainda assim, há proximidade com os valores de DAP dos tratamentos E-IR-A $(16,33 \mathrm{~cm})$ e E-IR-B $(16,97)$; o menor DAP foi obtido com o tratamento E-NIR-B $(13,89 \mathrm{~cm})$.

Resultados positivos com relação à irrigação também foram encontrados por Vellini et al. (2008). Os autores constataram diminuição nas características fisiológicas na medida em que se diminuía a frequência de irrigação (em proporções variáveis), o que corrobora com os resultados encontrados no experimento aqui relatado.

Durante o ano de 2004 (Figura 3) início do experimento, o critério de pesquisa teve como irrigar ou não irrigar as mudas, dado que a adubação presente de plantio era a mesma para

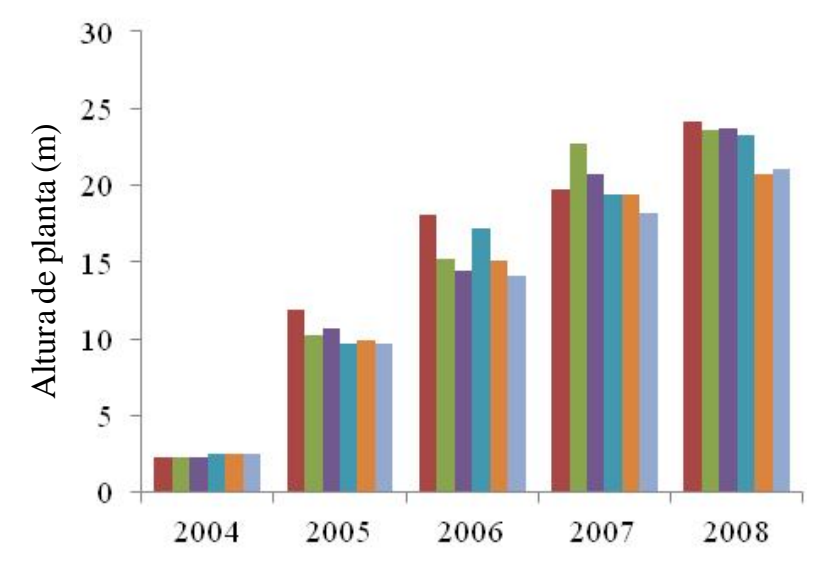

E-IR-A $\quad$ E-IR-B $\quad$ E-IR-C

E-NIR-A $=$ E-NIR-B $=\mathrm{E}-\mathrm{NIR}-\mathrm{C}$

E-IR-A - parcelas irrigadas e com $100 \%$ da adubação necessária; E-IR-B - parcelas irrigadas e com $50 \%$ da adubação necessária; E-IR-C - parcelas irrigadas e com $25 \%$ da adubação necessária; E-NIR-A - parcelas não irrigadas e com $100 \%$ da adubação necessária; E-NIR-B - parcelas não irrigadas e com $50 \%$ da adubação necessária; E-NIR-C - parcelas não irrigadas e com $25 \%$ da adubação necessária

Figura 3. Medidas de altura de plantas de eucalipto de 2004 a 2008 para os diferentes tratamentos todas. O valor médio para o eucalipto irrigado (tratamento 1) foi 2,33 m e para o não-irrigado (tratamento 2), 2,45 m.

Obteve-se a maior média de valores com o tratamento E-IRA, com 11,89 m. Houve predominância de valores próximos a este para as árvores irrigadas e com 100\% da adubação (Figura 3). Os tratamentos E-IR-B e E-IR-C apresentam valores próximos com 10,18 e 10,67 m, respectivamente. Para os tratamentos sem irrigação os valores de altura foram de 9,73 m, 9,88 m e 9,66 m para os tratamentos com 100, 50 e $25 \%$ de fertilização, respectivamente, sugerindo que nessa idade para tratamentos não irrigados a metade da adubação recomendada atingiria resultados próximos a um uso total de fertilizantes. Gomes et al. (2003) observaram que a adubação não trouxe diferenças significativas quando do crescimento de mudas em tubete fato que pode ter ocorrido em virtude da disponibilidade de potássio, nitrogênio e fósforo no substrato de plantio.

Em 2006 (Figura 3) observou-se tendência do tratamento EIR-A apresentar maiores valores de alturas. Neste período, referido tratamento apresentou média de $18,20 \mathrm{~m}$, seu tratamento sem irrigação correspondente a E-NIR-A apresentou máximo maior do que o valor médio do tratamento irrigado; apesar disto, observa-se que o valor médio continua abaixo da média do tratamento irrigado e dos $100 \%$ adubado. Entre os tratamentos não irrigados constatou-se proximidade de valores médios para os três níveis de adubação, confirmando a tendência do tratamento com $50 \%$ de fertilizantes de apresentar resultados viáveis, se comparado com o dos tratamentos sem irrigação, com $100 \%$ de adubação.

Em 2007 o tratamento irrigado com 50\% da adubação apresentou valores de 22,67 $\mathrm{m}$ de altura superando, em valores médios, a altura do tratamento irrigado com $100 \%$ da dose recomendada de fertilizantes. Para os tratamentos sem irrigação permaneceu a tendência do tratamento E-NIR-B, com maiores valores médios de altura das árvores quando comparado com o tratamento E-NIR-A.

O maior valor de altura foi apresentado pelo tratamento irrigado e $100 \%$ adubado, com 24,16 m de altura média das árvores. Com relação aos tratamentos sem irrigação o tratamento também com $100 \%$ da dose recomendada superou o tratamento com 50\% de adubação, com valores médios de 22,53 m.

Com relação aos dados de diâmetro à altura do peito, observou-se semelhança nos valores médios dos tratamentos E-IR-A, E-IR-B, E-IR-C e E-NIR-A em 2006 (Figura 4).

Em 2007 (Figura 4), é apresentada leve tendência para maiores valores de DAP com vista ao tratamento E-IR-B e menores valores para E-NIR-C.

No ano de 2008 notou-se diferença de que, quando comparados com os anos anteriores, E-IR-A supera E-IR-B, evidenciando que para o eucalipto sob condições de irrigação a aplicação da dose total de nutrientes recomendados pode implicar no aumento da produtividade da madeira.

Na Tabela 4 estão distribuídos as médias de altura de plantas e seus grupos, obtidos pelo Teste de Tukey e significativos a 5\%, referentes aos anos de 2005 a 2008. Em 2005 apenas o tratamento irrigado e $100 \%$ adubado, diferiu significativamente dos outros.

No ano de 2006 o tratamento irrigado e $100 \%$ adubado apresentou média estatisticamente equivalente à do tratamento 


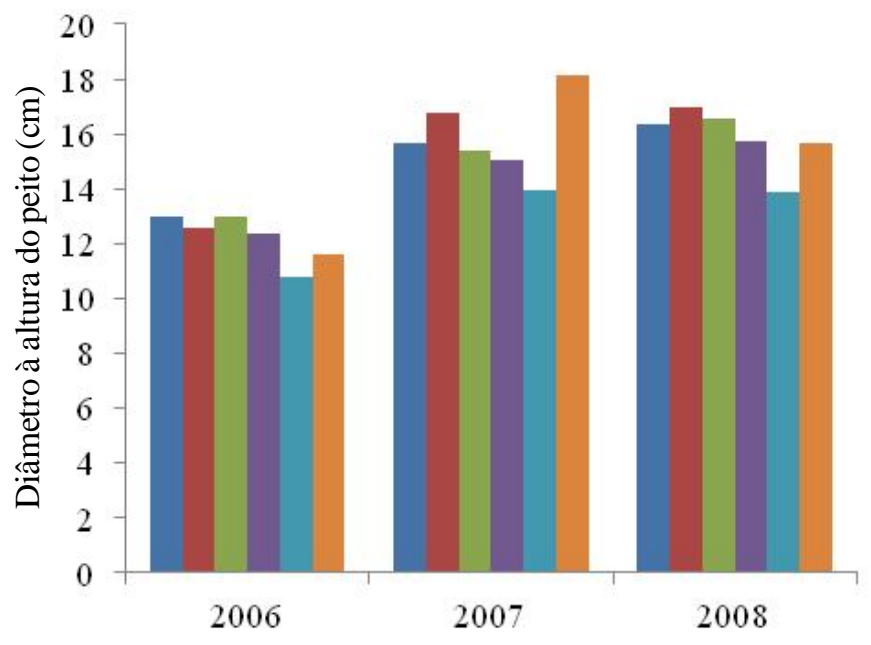

$=\mathrm{E}-\mathrm{IR}-\mathrm{A} \quad \mathrm{E}-\mathrm{IR}-\mathrm{B} \quad \mathrm{E}-\mathrm{IR}-\mathrm{C}$

E-NIR-A $₫$ E-NIR-B $\approx$ E-NIR-C

E-IR-A - parcelas irrigadas e com $100 \%$ da adubação necessária; E-IR-B - parcelas irrigadas e com $50 \%$ da adubação necessária; E-IR-C - parcelas irrigadas e com $25 \%$ da adubação necessária; E-NIR-A - parcelas não irrigadas e com $100 \%$ da adubação necessária; E-NIR-B - parcelas não irrigadas e com $50 \%$ da adubação necessária; E-NIR-C - parcelas não irigadas e com $25 \%$ da adubação necessária

Figura 4. Medidas de diâmetro à altura do peito (DAP) de plantas de eucalipto de 2004 a 2008, para os diferentes tratamentos

Tabela 4. Comparações entre médias da altura $(m)$ do eucalipto

\begin{tabular}{|c|c|}
\hline Tratamento & Médias (m) \\
\hline $\begin{array}{c}6 \text { (E-NIR-C) } \\
4 \text { (E-NIR-A) } \\
5 \text { (E-NIR-B) } \\
2 \text { (E-IR-B) } \\
3 \text { (E-IR-C) } \\
1 \text { (E-IR-A) }\end{array}$ & $\begin{array}{r}9,65 a \\
9,73 a \\
9,88 a \\
10,18 a \\
10,67 a \\
11,89 \mathrm{~b}\end{array}$ \\
\hline $\begin{array}{c}3 \text { (E-IR-C) } \\
6 \text { (E-NIR-C) } \\
5 \text { (E-NIR-B) } \\
2 \text { (E-IR-B) } \\
4 \text { (E-NIR-A) } \\
1 \text { (E-IR-A) }\end{array}$ & $\begin{array}{l}14,43 \mathrm{a} \\
14,58 \mathrm{a} \\
15,07 \mathrm{a} \\
15,23 \mathrm{a} \\
17,20 \mathrm{~b} \\
18,04 \mathrm{~b}\end{array}$ \\
\hline $\begin{array}{l}5 \text { (E-NIR-B) } \\
6 \text { (E-NIR-C) } \\
4 \text { (E-NIR-A) } \\
2 \text { (E-IR-B) } \\
3 \text { (E-IR-C) } \\
1 \text { (E-IR-A) }\end{array}$ & $\begin{array}{l}20,86 a \\
21,09 a b \\
22,76 a b \\
23,22 a b \\
23,79 a b \\
24,12 b\end{array}$ \\
\hline $\begin{array}{c}5 \text { (E-NIR-B) } \\
6 \text { (E-NIR-C) } \\
4 \text { (E-NIR-A) } \\
2 \text { (E-IR-B) } \\
3 \text { (E-IR-C) } \\
1 \text { (E-IR-A) }\end{array}$ & $\begin{array}{l}20,86 a \\
21,09 a b \\
22,76 a b \\
23,22 a b \\
23,79 a b \\
24,12 b\end{array}$ \\
\hline
\end{tabular}

* Para cada ano, as médias seguidas por uma mesma letra, não diferem estatisticamente (Tukey, $p>0,01$ )

E-IR-A - parcelas irrigadas e com $100 \%$ da adubação necessária; E-IR-B - parcelas irrigadas e com $50 \%$ da adubação necessária; E-IR-C - parcelas irrigadas e com $25 \%$ da adubação necessária; E-NIR-A - parcelas não irrigadas e com $100 \%$ da adubação necessária; E-NIR-B - parcelas não irrigadas e com $50 \%$ da adubação necessária; E-NIR-C - parcelas não irrigadas e com $25 \%$ da adubação necessária sequeiro 100\% adubado, de acordo com Tabela 4; em 2007 o tratamento irrigado e $50 \%$ adubado e o sequeiro $100 \%$ adubado apresentaram médias maiores e estatisticamente equivalentes, pertencendo a grupos iguais; em 2008 teve-se a menor média para tratamento irrigado e $50 \%$ adubado, pertencendo a grupos iguais todos os tratamentos sequeiros; maior valor de média de altura foi apresentado pelos dois tratamentos irrigados com 50 e $25 \%$ de nutrição recomendada.

Na Tabela 5 estão distribuídos as médias de diâmetro à altura do peito (DAP) e seus grupos, obtidos pelo Teste de Tukey e significativos a 5\%, referentes aos anos de 2005 a 2008, enquanto em 2006 os tratamentos irrigados com 50 e $25 \%$ e o sequeiro com $100 \%$ apresentaram médias estatisticamente equivalentes (Tabela 5).

Tabela 5. Comparações entre médias do diâmetro à al tura do peito - DAP $(\mathrm{cm})$ do eucalipto

\begin{tabular}{cll}
\hline Tratamento & & Médias (cm) \\
5 (E-NIR-B) & A. 2006 & \\
6 (E-NIR-C) & & $10,25 \mathrm{a}$ \\
4 (E-NIR-A) & $11,61 \mathrm{~b}$ \\
3 (E-IR-C) & $12,36 \mathrm{bc}$ \\
2 (E-IR-B) & $12,48 \mathrm{bc}$ \\
1 (E-IR-A) & & $12,58 \mathrm{bc}$ \\
& & $13,00 \mathrm{c}$ \\
\hline (E-NIR-B) & B. 2007 & \\
6 (E-NIR-C) & & $13,97 \mathrm{a}$ \\
4 (E-NIR-A) & & $14,38 \mathrm{ab}$ \\
3 (E-IR-C) & & $15,031 \mathrm{ab}$ \\
1 (E-IR-A) & & $15,40 \mathrm{abc}$ \\
2 (E-IR-B) & & $15,64 \mathrm{bc}$ \\
& & $16,70 \mathrm{c}$ \\
\hline (E-NIR-B) & C. 2008 & \\
6 (E-NIR-C) & & $13,97 \mathrm{a}$ \\
4 (E-NIR-A) & & $15,62 \mathrm{ab}$ \\
1 (E-IR-A) & & $15,71 \mathrm{ab}$ \\
3 (E-IR-C) & & $16,25 \mathrm{ab}$ \\
2 (E-IR-B) & $16,40 \mathrm{ab}$ \\
\hline
\end{tabular}

* As médias, para cada ano, seguidas de uma mesma letra, não diferem estatisticamente (Tukey, $p>0,01$ )

E-IR-A - parcelas irrigadas e com $100 \%$ da adubação necessária; E-IR-B - parcelas irrigadas e com $50 \%$ da adubação necessária; E-IR-C - parcelas irrigadas e com $25 \%$ da adubação necessária; E-NIR -A - parcelas não irrigadas e com $100 \%$ da adubação necessária; E-NIR-B - parcelas não irrigadas e com $50 \%$ da adubação necessária; E-NIR-C - parcelas não irrigadas e com $25 \%$ da adubação necessária

Referente a 2007 (Tabela 5) verificaram-se, no mesmo grupo, os tratamentos sequeiros com $100 \%$ e com $25 \%$ da recomendação nutricional; apenas no tratamento irrigado com $50 \%$ da adubação houve maior média.

Para o ano de 2008 (Tabela 5), observaram-se menores valores para tratamento de eucalipto não irrigado com $50 \%$ da dose recomendada. A proximidade entre os tratamentos não-irrigados com 25 e $100 \%$ da dose recomendada sugere que menor uso de fertilizantes pode inferir em resultados semelhantes se forem usadas altas dosagens na adubação. Barreiros et al. (2007) relataram, em seu experimento, que a adubação com lodo de esgoto em tratamentos de eucalipto ocasionou decréscimo na densidade da madeira, embora este evento tenha sido compensado pela maior produtividade da madeira.

Comparando a utilização do biossólido em tratamentos silviculturais de eucalipto, a adubação mineral resultou em 
semelhante produtividade de madeira, influenciando positivamente na nutrição das plantas (Rocha et al., 2004). Resultado semelhante não foi obtido por Galbiatti et al. (2007), no qual a adubação utilizando resíduo sólido orgânico urbano em doses acima de $20 \%$ causou efeito negativo no crescimento e desenvolvimento do eucalipto; em nível de irrigação tampouco houve diferenças estatísticas quando do uso do resíduo supracitado.

Ainda que os maiores valores de altura e DAP tenham sido ora de um tratamento, ora de outro, de acordo com a nutrição disponibilizada para a espécie ao longo dos anos, percebeu-se que a prevalência de maiores valores foi entre tratamentos irrigados. Reis et al. (2006) observaram, em experimento com diferentes clones de eucalipto aos 38 meses submetidos a variadas condições de hidratação das mudas, que embora valores de altura não tenham apresentado diferença estatística entre si, os dados de diâmetro e volume foram maiores nos tratamentos irrigados do que nos não-irrigados.

Em comparação com a prevalência de valores maiores dos parâmetros analisados entre os tratamentos irrigados, a literatura corrobora com os resultados encontrados e o fato de que a disponibilidade de água afeta o crescimento do eucalipto (Balieiro et al., 2008). Martins et al. (2008) relataram que o déficit hídrico afeta negativamente o crescimento e o desenvolvimento de mudas, em experimento realizado na Universidade Federal de Santa Maria, Rio Grande do Sul. Foi notória a influência nos aspectos morfológicos de mudas de E. grandis em diferentes aplicações de lâminas de irrigação tendo as lâminas com 12 e $14 \mathrm{~mm} \mathrm{~d}^{-1}$ contribuído mais significativamente para o crescimento das mudas (Lopes et al., 2007).

Na Tabela 6 constam o volume total de eucalipto em 2008 e o incremento médio anual (IMA,) por tratamento. O maior IMA $\left(77,6 \mathrm{~m}^{3} \mathrm{ha}^{-1}\right.$ ano $\left.^{-1}\right)$ foi obtido no tratamento $100 \%$ adubado e irrigado, havendo volume total para este talhão, de $376,1 \mathrm{~m}^{3} \mathrm{ha}^{-1}$.
Tabela 6. Volume total em $2008\left(\mathrm{~m}^{3} \mathrm{ha}^{-1}\right)$ e incremento médio anual -IM A, ( $\left.\mathrm{m}^{3} \mathrm{ha}^{-1} \mathrm{ano}^{-1}\right)$ do eucalipto

\begin{tabular}{lccc}
\hline Tratamento & Estatística & $\begin{array}{c}\text { Volume } \\
\left(\mathbf{m}^{3} \mathbf{h a}^{-1}\right)\end{array}$ & $\begin{array}{c}\text { IMA, } \\
\left(\mathbf{m}^{3} \mathbf{h a}^{-1} \mathrm{ano}^{-1}\right)\end{array}$ \\
\hline 1 (E-IR-A) & Médias & 376,1 & 77,6 \\
& C.V. & 12,7 & \\
\hline 2 (E-IR-B) & I.C. $95 \%$ & 20,2 & \\
& Médias & 328,6 & 67,8 \\
& C.V. & 22,5 & \\
\hline 3 (E-IR-C) & I.C. $95 \%$ & 35,9 & \\
& Médias & 365,8 & 75,4 \\
& C.V. & 9,5 & \\
\hline 4 (E-NIR-A) & I.C. $95 \%$ & 15,1 & \\
& Médias & 334,9 & 69,1 \\
& C.V. & 16,4 & \\
\hline 5 (E-NIR-B) & I.C. $95 \%$ & 26,0 & \\
& Médias & 271,8 & 56,0 \\
& C.V. & 33,5 & \\
\hline 6 (E-NIR-C) & I.C. $95 \%$ & 53,3 & \\
& Médias & 304,9 & 62,9 \\
& C.V. & 20,1 & \\
\hline & I.C. $95 \%$ & 32,0 & \\
\hline
\end{tabular}

E-IR-A - parcelas irrigadas e com $100 \%$ da adubação necessária; E-IR-B - parcelas irrigadas e com $50 \%$ da adubação necessária; E-IR-C - parcelas irrigadas e com $25 \%$ da adubação necessária; E-NIR-A - parcelas não irrigadas e com $100 \%$ da adubação necessária; E-NIR-B - parcelas não irrigadas e com $50 \%$ da adubação necessária; E-NIR-C - parcelas não irrigadas e com $25 \%$ da adubação necessária

Menores valores de IMA $\left(56 \mathrm{~m}^{3} \mathrm{ha}^{-1}\right.$ ano $\left.^{-1}\right)$ e volume total $(271,8$ $\mathrm{m}^{3} \mathrm{ha}^{-1}$ ) foram observados no tratamento com metade da dose recomendada de nutrição e submetido a condições de nãoirrigação. No Brasil um bom manejo de produção alcança no máximo $50 \mathrm{~m}^{3} \mathrm{ha}^{-1} \mathrm{ano}^{-1}$ (Agrianual, 2010).

Andrade et al. (2006) obtiveram volumes, para uma floresta com 86 meses de idade de E. grandis, de $393,5 \mathrm{~m}^{3} \mathrm{ha}^{-1}$ (tratamento com $130 \mathrm{~g}$ de fosfato parcialmente Solubilizado (FAPS) e 148 g N-P-K(10-20-10) no sulco e 146 g NPK(10-20-

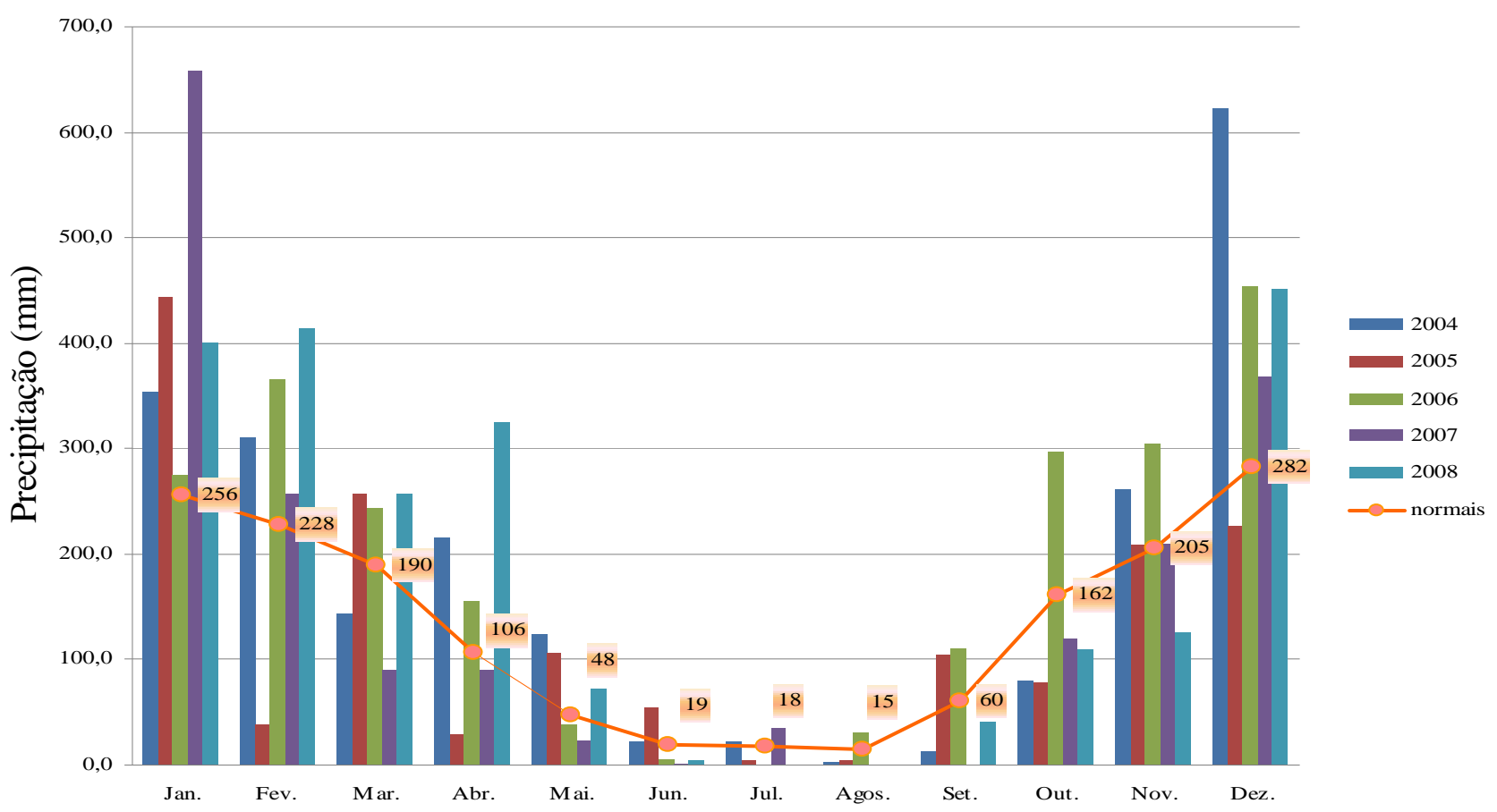

Figura 5. Precipitação mensal entre os anos de 2004 a 2008 na Fazenda Escola, em U beraba, M inas G erais 
10) em cobertura); $523,2 \mathrm{~m}^{3} \mathrm{ha}^{-1}$ (tratamento caracterizado por correção de 1,500 g calcário e $400 \mathrm{~g}$ Termofosfato + $300 \mathrm{~g}$ N-P$\mathrm{K}(10-10-10)+200$ g N-P-K(20-00-15) a lanço, em faixa, no sulco e em cobertura, respectivamente) e $497 \mathrm{~m}^{3} \mathrm{ha}^{-1}$ (400 g termofosfato $+300 \mathrm{~g} \mathrm{~N}-\mathrm{P}-\mathrm{K}(10-10-10)+200 \mathrm{~g} \mathrm{NPK}(20-00-15)$ em faixa, no sulco e em cobertura, respectivamente). Em comparação com o volume obtido neste experimento para os tratamentos de eucalipto não-irrigado e com $100 \%$ de adubação recomendada $\left(335 \mathrm{~m}^{3} \mathrm{ha}^{-1}\right)$ o valor é satisfatório considerandose que a floresta se encontrava, em 2008, com 5 anos de idade. Ainda assim, resultados mais expressivos poderiam ser obtidos no experimento, dado às características sazonais da região em que o experimento foi realizado.

Pelo balanço hídrico normal de Thornthwaite \& Mather (1955), a precipitação anual normal da região de Uberaba é de 1589 mm. Observa-se, na Figura 5, sobretudo nos meses chuvosos do período de estudo, que as precipitações mensais superam em até mais do dobro da normal mensal.

Desta forma, a oferta mensal pluvial pôde colaborar decisivamente nas comparações dos tratamentos irrigados e de sequeiro, ocasionando pequena diferença de valores. Inferese também, pela Figura 5, a periodicidade de um ano chuvoso ser seguido de um ano de estiagem quando comparado com o anterior. Para o mês de janeiro a literatura relata que tendências positivas de pluviosidade podem estar relacionadas com o evento El Niño (Grimm, 2003).

\section{ConClusÕes}

1. Os tratamentos irrigados apresentaram maiores índices biométricos (altura e diâmetro à altura do peito).

2. A proximidade de valores de altura e diâmetro à altura do peito entre tratamentos irrigados e de sequeiro, pode ter sido consequência de anos mais chuvosos que a média normal da região.

3. Maiores valores de incremento médio anual (IMA) foram obtidos para o tratamento irrigado e $100 \%$ adubado.

4. Menores valores de incremento médio anual (IMA) foram encontrados para o tratamento não irrigado e com 50\% da dose nutricional recomendada.

\section{LITERATURA CITADA}

Agrianual. Anuário da Agricultura Brasileira. São Paulo: FNP Consultoria e Comércio, 2010. 520p.

Alencar, C. A. B. de; Cunha, F. F. da; Martins, C. E.; Cóser, A. C.; Rocha, W. S. D. da; Araújo, R. A. S. Irrigação de pastagem: Atualidade e recomendações para uso e manejo. Revista Brasileira de Zootecnia, v.38, p.98-108, 2009.

Almeida, A. C. de; Soares, J. V. Comparação entre uso de água em plantações de Eucalyptus grandis e floresta ombrófila densa (Mata Atlântica) na costa leste do Brasil. Revista Árvore, v.27, p.159-1702003.
Andrade, G. de C.; Bellote, A. F. J; Silva, H. D. da; Dedecek, R. A.; Gava, J. L. Efeito da aplicação de lixo urbano compostado e de adubos minerais no solo e na produtividade de Eucalyptus grandis. Pesquisa Florestal Brasileira, v.53, p. 39-66, 2006.

Balieiro, F. de C.; Oliveira, W. C.; Pereira, M. G.; A., L. H. C. dos; Picollo, M. de C.; Jaccoud, C. F. Fertilidade e carbono do solo e uso da água pelo eucalipto numa topossequência em Seropédica, RJ. Revista Árvore, v.32, p.153-162, 2008.

Barreiros, R. M.; Gonçalves, J. L. de M.; Sansígolo, C. A.; Poggiani, F. Modificações na produtividade e nas características físicas e químicas da madeira de Eucalyptus grandis causadas pela adubação com lodo de esgoto tratado. Revista Árvore, v.31, p.103-111, 2007.

Brasil. Resolução CONAMA n.20, de 18 de junho de 1986. Estabelece a classificação de águas doces, salobras e salinas. Diário Oficial da República Federativa do Brasil, Brasília, 1986, p.11.356.

Cordeiro, S. A.; Silva, M. L. da; Jacovine, L. A. G.; Valverde, S. R.; Soares, N. S. Contribuição do fomento do órgão florestal de Minas Gerais na lucratividade e na redução de riscos para produtores rurais. Revista Árvore, v.34, p.367-376, 2010.

FAO - Food and Agriculture Organization of the United Nations - National Forest assessments of the Food and Agriculture Organization of the United Nations: Country Projects Overview Brazil. 2010. 52p.

Galbiatti, J. A.; Lui, J. J.; Sabonaro, D. Z.; Bueno, L. F.; Silva, V. L. da. Formação de mudas de eucalipto com utilização de lixo orgânico e níveis de irrigação calculados por dois métodos. Engenharia Agrícola, v.27, p.445-455, 2007.

Gomes, J.M.; Couto, L.; Leite, H. G.; Xavier, A.; Garcia, S. L. R. Crescimento de mudas de Eucalyptus grandis em diferentes tamanhos de tubetes e fertilização N-P-K. Revista Árvore, v.27, p.113-127, 2003.

Grimm, A. M. The El Niño impact on the summer monsoon in Brazil: regional processes versus remote influences. Journal of Climate, v.16, p.263-280, 2003.

Gruber, Y. B. G.; Tavares, A. C. S.; Detomini, E. R.; Coelho, R. D. Eucalipto irrigado tem de produzir mais: Quanto é preciso aumentar a produtividade para custear cada sistema de irrigação. In: Agrianual 2006: Anuário da agricultura brasileira. São Paulo: Instituto FNP, p.318-321, 2006.

Lopes, J. L. W.; Guerrini, I. A.; Saad, J. C. C. Qualidade de mudas de eucalipto produzidas sob diferentes lâminas de irrigação e dois tipos de substrato. Revista Árvore, v.31, p.835-843, 2007.

Lopes, J. L. W.; Guerromo, I. A.; Saad, J. C. C.; Silva, M. R. da. Efeitos da irrigação na sobrevivência, transpiração e no teor relativo de água na folha em mudas de Eucalyptus grandis em diferentes substratos. Scientia Forestalis, v.68, p.97-106, 2005.

Martins, F. B.; Streck, N. A.; Silva, J. C. da; Morais, W. W.; Susin, F.; Navroski, M. C.; Vivian, M. A. Deficiência hídrica no solo e seu efeito sobre transpiração, crescimento e desenvolvimento de mudas de duas espécies de eucalipto. Revista Brasileira de Ciência do Solo, v.32, p.1297-1306, 2008. 
Pizarro, F. Riegos localizados de alta frequencia: goteo, microaspersion, exudacion. Madri: Mundi-Prensa, 1990. 470p.

Ranzani, G. Manual de levantamento de solo. Rio de Janeiro: Edgard Blücher, 1969. 265p.

Reis, G. G. dos; Reis, M. das G. F.; Fontan, I. da C. I.; Monte, M. A.; Gomes, A. N.; Oliveira, C. H. R. de. Crescimento de raízes e da parte aérea de clones de híbridos de Eucalyptus grandis x Eucalyptus urophylla e de Eucalyptus camaldulensis x Eucalyptus spp submetidos a dois regimes de irrigação no campo. Revista Árvore, v.30, p.921-931, 2006.

Rocha, G. N.; Gonçalves, J. L. M.; Moura, I. M. Mudanças da fertilidade do solo e crescimento de um povoamento de Eucalyptus grandis fertilizado com biossólido. Revista Brasileira de Ciência do Solo, v.28, p.623-639, 2004.

SBS - Sociedade Brasileira de Silvicultura. Fatos e números do Brasil Florestal. São Paulo: SBS, 2008. 92p.

Shimizu, J. Y. Pinus na silvicultura brasileira. Revista da Madeira, v.16, p.4-14, 2006.
Silva, A. L. da; Faria, M. A. de; Reis, R. P. Viabilidade técnicoeconômica do uso do sistema de irrigação por gotejamento na cultura do cafeeiro. Revista Brasileira de Engenharia Agrícola e Ambiental, v.7, p.37-44, 2003.

Silva, W. da; Sediyama, T.; Silva, A. A. da; Cardoso, A. A. Índice de consumo e eficiência em uso da água em eucalipto, submetido a diferentes teores de água em convivência com Braquiária. Revista Floresta, v.34, p.325-335, 2004.

Souza, M. J. H.; Ribeiro, A.; Leite, H. G.; Leite, F. P.; Minuzzi, R. B. Disponibilidade hídrica do solo e produtividade do eucalipto em três regiões da Bacia do Rio Doce. Revista Árvore, v.30, p.399-410, 2006.

Thornthwaite, C. W.; Mather, J. R. The water balance. Publications in climatology. New Jersey: Drexel Institute of Technology, 1955. 104p.

Vellini, A. L. T. T.; Paula, N. F. de; Alves, P. L. da C. A.; Pavani, L. C.; Bonine, C. A. V.; Scarpinati, E. A.; Paula, R. C. de. Respostas fisiológicas de diferentes clones de eucalipto sob diferentes regimes de irrigação. Revista Árvore, v.32, p.651-663 2008. 